(2) Open Access Full Text Article

\title{
Does celecoxib inhibit agomelatine metabolism via CYP2C9 or CYPIA2?
}

This article was published in the following Dove Press journal:

Drug Design, Development and Therapy

\section{Umit Yasar}

Department of Medical Pharmacology, Hacettepe University, Faculty of Medicine, Ankara, Turkey
Correspondence: Umit Yasar Department of Medical Pharmacology, Hacettepe University, Faculty of Medicine, Sihhiye, Ankara 06I00, Turkey Tel +90 3/2 305 I087

Email uyasar@hacettepe.edu.tr

\section{Dear editor}

He et al have reported inhibitory effect of celecoxib on agomelatine metabolism in rat/ human liver microsomes, recombinant human cytochrome P450 (CYP) 2C9 in vitro and in Sprague Dawley rats in vivo. ${ }^{1}$

I would like to emphasize two important points related to celecoxib-agomelatine interaction. Firstly, according to an article cited by He et al written by Liu et al, refers to the metabolism of agomelatine, CYP1A2 and CYP3A4 are the major CYP enzymes but not CYP2C9. ${ }^{2}$ In that study, Liu et al characterized novel metabolic pathways and CYP-mediated metabolism of agomelatine using metabolomic approaches. ${ }^{2}$ Among the 39 metabolites of agomelatine determined, 19 have been produced by CYP enzymes, mainly by CYP1A2. He et al cited another review article written by Sansone and Sansone as a reference to the role of CYP2C9 in the metabolism of agomelatine; however, that article also indicated CYP1A2 as the main responsible enzyme for agomelatine metabolism, and nothing was mentioned about the contribution of CYP2C9. ${ }^{3}$ In earlier in vitro studies and the European Medicines Agency assessment report, CYP1A2, CYP2C9 and CYP2C19 have been suggested as the enzymes responsible for the metabolism of agomelatine. These in vitro data should be carefully interpreted because the type of in vitro drug metabolism system and the concentrations of the drug used in those studies may not directly be correlated with in vivo conditions. For example, in $\mathrm{He}$ et al, inhibitory effect of celecoxib was not present at $10 \mu \mathrm{M}$ and was observed at $50 \mu \mathrm{M}$ in liver microsomes and this inhibition pattern does not reflect in vivo conditions. ${ }^{1}$ Therefore, considering the findings in literature, the contribution of CYP2C9 in agomelatine metabolism seems to be minor and needs to be clarified in further studies.

Secondly, celecoxib can interact with other drugs metabolized by CYPs other than CYP2C9. For example, celecoxib has been well documented to inhibit CYP2D6mediated metabolism of metoprolol to $\alpha$-hydroxymetoprolol in vivo in humans by Werner et al. ${ }^{4}$ Also, celecoxib has been reported to inhibit CYP1A2 activity in vitro. ${ }^{5}$ That may be the case for agomelatine-celecoxib interaction, which has not been discussed by $\mathrm{He}$ et al. ${ }^{1}$

As a conclusion, according to the literature data, CYP2C9 does not seem to have a major role in agomelatine metabolism, while a possible interaction between agomelatine and celecoxib cannot be ruled out. Inhibition of other CYPs, such as CYP1A2, via celecoxib should also be taken into account in such studies. Further studies considering 
the above-mentioned issues may clarify the mechanism for celecoxib-agomelatine interaction.

\section{Disclosure}

The author reports no conflicts of interest in this communication.

\section{References}

1. He J, Fang P, Zheng X, et al. Inhibitory effect of celecoxib on agomelatine metabolism in vitro and in vivo. Drug Des Devel Ther. 2018;12: 513-519.
2. Liu X, Lu YF, Guan X, Zhao M, Wang J, Li F. Characterizing novel metabolic pathways of melatonin receptor agonist agomelatine using metabolomic approaches. Biochem Pharmacol. 2016;109:70-82.

3. Sansone RA, Sansone LA. Agomelatine: a novel antidepressant. Innov Clin Neurosci. 2011;8(11):10-14.

4. Werner U, Werner D, Rau T, Fromm MF, Hinz B, Brune K. Celecoxib inhibits metabolism of cytochrome P450 2D6 substrate metoprolol in humans. Clin Pharmacol Ther. 2003;74(2):130-137.

5. Karjalainen MJ, Neuvonen PJ, Backman JT. Celecoxib is a CYP1A2 inhibitor in vitro but not in vivo. Eur J Clin Pharmacol. 2008;64(5): 511-519. 


\section{Authors' reply}

Jiayang $\mathrm{He}^{1}$

Ping Fang ${ }^{2}$

Xiang Zheng ${ }^{2}$

Chenchen Wang ${ }^{2}$

Tenghui Liu²

Bowen Zhang ${ }^{2}$

Jian Wen ${ }^{2}$

Ren-Ai Xu ${ }^{3}$

'The First Hospital of Jiaxing, Jiaxing, Zhejiang, China; ${ }^{2}$ Department of Pharmacology, School of Pharmacy of Wenzhou Medical University, Wenzhou, Zhejiang, China; ${ }^{3}$ The First Affiliated Hospital of Wenzhou Medical University, Wenzhou, Zhejiang, China

Correspondence: Ren-Ai Xu

The First Affiliated Hospital of Wenzhou Medical University,

Wenzhou 32500, Zhejiang, China

Email ysxurenai@hotmail.com

\section{Dear editor}

Referring to the comments of Yasar on our latest publication about the inhibitory effect of celecoxib on agomelatine metabolism in vitro and in vivo, ${ }^{1}$ we cordially appreciate it and would like to give some responses.

We feel sorry that our statement about the metabolism of agomelatine may not be very accurate. Actually, it has already been reported that agomelatine is metabolized via CYP1A2 (90\%) and to a lesser extent via CYP2C9 and CYP2C19. ${ }^{2}$ Moreover, 90\% CYP1A2 and 10\% CYP2C9 contribute to the metabolism of agomelatine in hepatic as reported on DRUGBANK. ${ }^{3}$ So, we mean that CYP1A2 and CYP2C9 are the main CYP enzymes which can rapidly metabolize agomelatine in the liver. Although we recognize that CYP1A2 plays a more important role in agomelatine metabolism, our in vitro experiment, which aimed to assess the catalytic activities of CYP2C9 toward agomelatine by using recombinant CYP2C9*1, showed that CYP2C9 is able to contribute to agomelatine 7-desmethylation and 3-hydroxylation metabolism to some extent. The Michaelis-Menten curve plots for CYP2C9*1 are shown in Figure 1, and the corresponding kinetic parameters $\left(\mathrm{V}_{\max }, \mathrm{K}_{\mathrm{m}}\right.$, intrinsic clearance) are summarized in Table 1. The $\mathrm{K}_{\mathrm{m}}$ values of 7-desmethyl agomelatine and 3-hydroxy agomelatine were 13.40 and $31.96 \mu \mathrm{M}$, respectively, which indicated that the affinity of CYP2C9 and the substrate agomelatine is great. Considering that several CYP450 enzymes may be involved in the metabolism of agomelatine and may potentially complement one another, especially when the major metabolic pathway is defective, we think it is necessary to investigate the effect of CYP2C9 activity. The effect of CYP2C9 activity does not conflict with the contribution of CYP1A2 in agomelatine metabolism.

Celecoxib, as Yasar mentioned, is a known CYP2D6 inhibitor and may be a potent CYP1A2 inhibitor. However, CYP2C9 is one of the major enzymes for celecoxib. ${ }^{4-6}$ Given that celecoxib and agomelatine are both CYP2C9 substrates, therefore, we just infer that the increase in agomelatine exposure in vivo may be caused by the competitive inhibitory effect of celecoxib on CYP2C9 to a certain degree. In brief, our results showed the effect of CYP2C9 on the metabolism of agomelatine, while not ruling out CYP1A2. As for CYP1A2, our paper reported, "However, given that CYP1A2 play an important role in agomelatine metabolism, our further study must be focus on the studies that whether celecoxib also has the inhibitory effect on CYP1A2 activity."
A

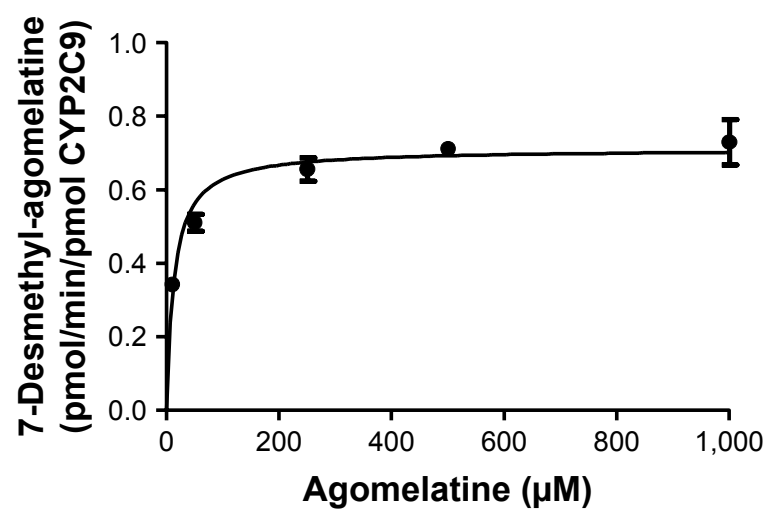

B

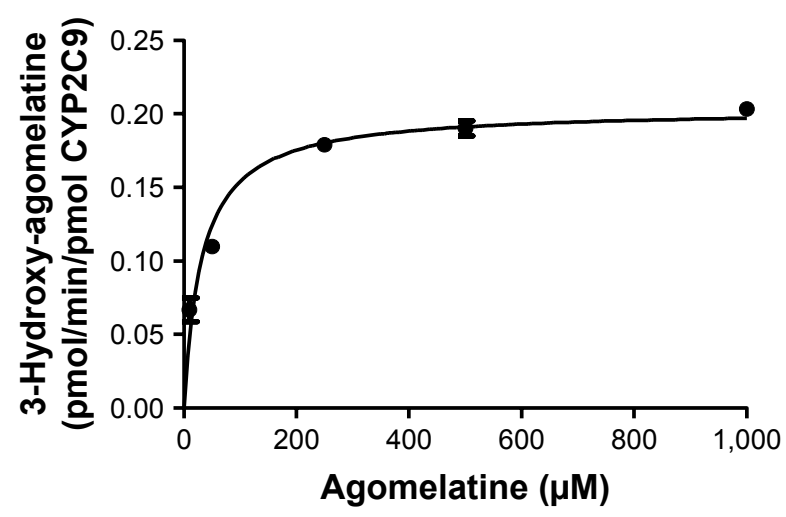

$\rightarrow$ CYP2C9*1

Figure I Michaelis-Menten curves of the enzymatic activity of CYP2C9 wild type toward agomelatine 7-desmethylation (A) and 3-hydroxylation (B). 
Table I Kinetic parameters for metabolite activities of CYP2C9* I against agomelatine

\begin{tabular}{llll}
\hline Metabolites & $\begin{array}{l}\mathbf{V}_{\max }(\mathbf{p m o l} / \\
\mathbf{m i n} / \mathbf{p m o l} \\
\mathbf{P 4 5 0})\end{array}$ & $\mathbf{K}_{\mathrm{m}}(\mu \mathrm{M})$ & $\begin{array}{l}\text { Clint } \\
\left(\mathbf{V}_{\max } / \mathbf{K}_{\mathrm{m}}\right)\end{array}$ \\
\hline 7-Desmethyl-agomelatine & $0.71 \pm 0.03$ & $13.40 \pm 2.23$ & $0.0540 \pm 0.0078$ \\
3-Hydroxy-agomelatine & $0.20 \pm 0.00$ & $31.96 \pm 2.29$ & $0.0064 \pm 0.0004$ \\
\hline
\end{tabular}

In addition, it is true that the in vitro results may not be directly correlated with the in vivo results. Moreover, the results may be different in rats and humans. Our results from in vitro and in vivo studies in rats just can offer a reference on clinical medication. Further studies should focus on the clinical research based on the data from in vitro and animal studies.

In conclusion, we found that celecoxib has an inhibitory effect on the metabolism of agomelatine both in vivo and in vitro. Also, the inhibitory effect could be explained by CYP2C9, but other reasons should be further studied.

\section{Disclosure}

The authors report no conflicts of interest in this communication.

\section{References}

1. He J, Fang P, Zheng X, et al. Inhibitory effect of celecoxib on agomelatine metabolism in vitro and in vivo. Drug Des Devel Ther. 2018;12: 513-519.

2. Green B. Focus on agomelatine. Curr Med Res Opin. 2011;27(4): 745-749.

3. DRUGBANK. Agomelatine. Available from: https://www.drugbank.ca/ drugs/DB06594.

4. Chan AT, Zauber AG, Hsu M, et al. Cytochrome P450 2C9 variants influence response to celecoxib for prevention of colorectal adenoma. Gastroenterology. 2009;136(7):2127-2136.e1.

5. Daly AK, Rettie AE, Fowler DM, Miners JO. Pharmacogenomics of CYP2C9: functional and clinical considerations. J Pers Med. 2017; 8(1):E1.

6. Sandberg M, Yasar U, Stromberg P, Hoog JO, Eliasson E. Oxidation of celecoxib by polymorphic cytochrome P450 2C9 and alcohol dehydrogenase. Br J Clin Pharmacol. 2002;54(4):423-429.

Dove Medical Press encourages responsible, free and frank academic debate. The content of the Drug Design, Development and Therapy 'letters to the editor' section does not necessarily represent the views of Dove Medical Press, its officers, agents, employees, related entities or the Drug Design, Development and Therapy editors. While all reasonable steps have been taken to confirm the content of each letter, Dove Medical Press accepts no liability in respect of the content of any letter, nor is it responsible for the content and accuracy of any letter to the editor.

\section{Publish your work in this journal}

Drug Design, Development and Therapy is an international, peerreviewed open-access journal that spans the spectrum of drug design and development through to clinical applications. Clinical outcomes, patient safety, and programs for the development and effective, safe, and sustained use of medicines are the features of the journal, which has also been accepted for indexing on PubMed Central. The manuscript management system is completely online and includes a very quick and fair peer-review system, which is all easy to use. Visit http://www.dovepress.com/testimonials.php to read real quotes from published authors. 